\title{
Cavity-Enhanced Measurements of Benzene for Environmental Monitoring
}

\author{
Mhanna Mhanna, Guangle Zhang, Noushad Kunnummal, Aamir Farooq
}

\begin{abstract}
A mid-infrared laser-based sensor is designed and demonstrated for trace detection of benzene at ambient conditions. The sensor is based on a distributed feedback inter-band cascade laser operating near $3.3 \mu \mathrm{m}$ and off-axis cavity-enhanced absorption spectroscopy. A multidimensional linear regression algorithm was applied to enable benzene measurements in the presence of interfering species, such as ethylene, methane and water vapor. A minimum detection limit of $2 \mathrm{ppb}$ was achieved for benzene at an integration time of 6 seconds; the detection limit reduces to $200 \mathrm{ppt}$ in dry conditions. A cross-sensitivity analysis was performed to study the effect of interfering species on benzene measurements. The sensor can be used to detect tiny leaks of benzene in petrochemical facilities and to monitor air quality in residential and industrial areas. The sensor performance was demonstrated by measuring air samples collected from various locations such as a petrol station, parking garage and ambient air.

Index Terms- Environmental monitoring, Gas detectors, Infrared sensors, Leak detection, Optical sensors, Pollution measurement, Sensor systems, Spectroscopy.
\end{abstract}

\section{INTRODUCTION}

$\mathrm{B}$ ENZENE $\left(\mathrm{C}_{6} \mathrm{H}_{6}\right)$ is found in air from various natural and anthropogenic emission sources, such as fires and volcanic emissions [1], gasoline service stations, vehicle exhaust, refineries, and petrochemical processing facilities [2]. Workers in petrochemical industries / gasoline stations, drivers of gasoline delivery tankers and motorcar service mechanics are, therefore, exposed to ppb-ppm levels of benzene [3]. Benzene is is a key ingredient in many industrial processes, and its usage threatens the health of workers who are daily exposed to high benzene concentrations. It was reported that 184 persons in rubber coat manufacturing factory suffered from chronic benzene poisoning, where 24 of them were taken to hospital and 2 died [4]. In addition, solvents used for colored ink in printers contain $70-75 \%$ benzene while those for black ink contain $30-35 \%$ benzene, which is proven to lead to severe poisoning among pressmen [5]. The manufacturing of resins, plastics, dyes, drugs, detergents, etc.

This paper was submitted for review on 9/7/2020. This work was funded by the Environmental Protection Department (EPD) of Saudi Aramco.

Mhanna Mhanna is a PhD student in mechanical engineering at King Abdullah University of Science and Technology, Thuwal, 23955, Saudi Arabia (e-mail: mhanna.mhanna@kaust.edu.sa).

Guangle Zhang is a post-doctoral fellow at King Abdullah University of Science and Technology, Thuwal, 23955, Saudi Arabia (e-mail: guangle.zhang@kaust.edu.sa).

Noushad Kunnummal is a Research Manager at Environmental Protection Department, Saudi Aramco, Dhahran, Saudi Arabia (e-mail: noushad.kunnummal@aramco.com).

Aamir Faroog is an Associate Professor of mechanical engineering at King Abdullah University of Science and Technology, Thuwal, 23955, Saudi Arabia (e-mail: aamir.farooq@kaust.edu.sa). include wide usage of benzene [6]. The production of benzene in petrochemical facilities may also emit benzene in the atmosphere. In developing countries like India, solid biofuels are burnt to meet household energy requirements. This results in significantly large emission of benzene compared to other VOCs like toluene [7]. It has been reported that burning biomass fuel for cooking could lead to premature deaths [8].

The World Health Organization (WHO) categorizes benzene as a major public health concern [9]. Fatal diseases such as cancer and aplastic anemia have been linked to human exposure to benzene [10 - 12]. Regulations have been made increasingly stringent to control the emissions of air pollutants $[13,14]$. These regulations led the Occupational Safety and Health Administration of the Unites States (OSHA) to set the recommended 8-hour exposure limit of benzene to $100 \mathrm{ppb}$ [15]. There exist several sensors based on a variety of techniques that can measure benzene concentration. The most popular ones are based on gas chromatography and mass spectrometry [16]. However, these devices are typically bulky, expensive and require periodic calibration. They also require extractive gas sampling and the typical measurement time can be up to a few minutes [17]. Benzene can also be measured with sensors that utilize porous polycrystalline resistors [18]. However, using such sensors is impractical for field measurements as the device needs to be regenerated, i.e., it has to be heated to $150{ }^{\circ} \mathrm{C}$ after each measurement in order to desorb the gases [19]. Secondly, such techniques provide low sensitivity as well as poor selectivity [20]. Another class of detectors are based on electrochemical technology, where an electrode either oxidizes or reduces the target species so that its concentration can be calculated from the resulting current [21]. However, these detectors are usually not selective to a 
particular VOC, and thus they suffer from significant interference issues [22].

The US Environmental Protection Agency (EPA) has recently affirmed that there is a dire demand for new and improved benzene sensors, since the commercial devices lack in many respects [23]. According to the reference exposure level (REL) of the National Institute for Occupational Safety and Health (NIOSH), the short time exposure limit (STEL) of benzene is $1 \mathrm{ppm}$, while the time-weighted average (TWA), which represents the average concentration over an 8-h working day, is $100 \mathrm{ppb}$ [24]. In order to meet these recommendations, it is highly important to have sensors that can detect ppb levels of benzene accurately and in real-time at various facilities where benzene emissions are likely. The minimum detection limit of such sensors should be lower than $100 \mathrm{ppb}$ while having a wide dynamic range, in parallel to having low interference from other species. Laser-based sensors can meet many of the desired features of benzene sensing. Previously, a laser-based sensor was developed for benzene [25], where it was shown that this sensor can achieve minimum detection limit of 12 ppb for 200 seconds integration time. However, this sensor operated at a wavelength $(\sim 1038$ $\mathrm{cm}^{-1}$ or $\left.9.64 \mu \mathrm{m}\right)$ which had high interference from ozone and ethylene, and even trace quantities of these species can considerably affect benzene measurements at the selected wavelength. Another work [26] measured benzene and toluene in the wavelength region near $10 \mu \mathrm{m}$ using a QCL and reported benzene detection limit of $260 \mathrm{ppb}$. Benzene was also measured near $16550 \mathrm{~cm}^{-1}$ using CRDS (cavity ringdown spectroscopy), where the mirrors were heated up to $70{ }^{\circ} \mathrm{C}$ to prevent benzene condensation [27]. Recently, a laser-based benzene sensor was developed by Sur et al. [28] with a detection limit of $200 \mathrm{ppb}$. The operating wavelength of this sensor $\left(\sim 3090 \mathrm{~cm}^{-1}\right.$ or $\left.3.4 \mu \mathrm{m}\right)$ suffers from significant interference from isoprene which can exceed the absorption of benzene at various sites [29]. In addition, ethylene and methane might be significant in some geographic locations, especially in petrochemical refineries, which can also induce interference errors in benzene measurement at this wavelength. Moreover, although the quoted detection limits of the two laser-based sensors [25, 28] are in ppb range, measurements carried out in practical environments show effective performance at much higher benzene concentrations.

In this work, we show the development of a laser-based sensor for measuring trace amounts of benzene in practical environments. Our sensor is based on off-axis cavity-enhanced absorption spectroscopy (OA-CEAS) [30] and a tunable distributed feedback inter-band cascade laser (DFB-ICL) operating near $3.3 \mu \mathrm{m}$. The sensor wavelength was selected carefully to minimize absorption interference from the main constituents of ambient air. Wavelength scanning and multidimensional linear regression were then used to remove the remaining interferences. The sensor achieved a detection limit of $2 \mathrm{ppb}$ in practical environments and thus surpassed the performance of previous laser-based sensors. In cases where other TEX (toluene, ethylbenzene and xylenes) species are present in appreciable amounts, then this sensor will report total BTEX concentration which is still useful for air quality monitoring. However, as mentioned previously, there are many situations where benzene is the primary pollutant. Table
I shows a comparison of the sensor developed in this work and the previous laser-based benzene sensors.

TABLE I

Comparison BetWeEn Previous BenZene Laser Sensors and THIS WORK

\begin{tabular}{cccccc}
\hline \hline Sensor & $\begin{array}{c}\text { Operating } \\
\text { wavelength } \\
(\mu \mathrm{m})\end{array}$ & $\begin{array}{c}\text { Effective } \\
\text { path- } \\
\text { length } \\
(\mathrm{m})\end{array}$ & $\begin{array}{c}\text { Interfering } \\
\text { species }\end{array}$ & $\begin{array}{c}\text { Minimum } \\
\text { detection } \\
\text { limit in } \\
\mathrm{N}_{2}(\mathrm{ppb})\end{array}$ & $\begin{array}{c}\text { Minimum } \\
\text { detection } \\
\text { limit in } \\
\text { real air } \\
(\mathrm{ppb})\end{array}$ \\
\hline $\begin{array}{c}\text { Lewicki } \\
\text { et al. } \\
{[25]}\end{array}$ & 9.64 & 76 & $\begin{array}{c}\mathrm{C}_{2} \mathrm{H}_{4}, \\
\mathrm{H}_{2} \mathrm{O}, \mathrm{O}_{3}\end{array}$ & 12 & $>12$ \\
\hline $\begin{array}{c}\text { Sur et } \\
\text { al. [28] }\end{array}$ & 3.4 & 63 & $\begin{array}{c}\mathrm{C}_{2} \mathrm{H}_{4}, \\
\mathrm{H}_{2} \mathrm{O}, \mathrm{C}_{5} \mathrm{H}_{8}\end{array}$ & 200 & $>200$ \\
\hline $\begin{array}{c}\text { This } \\
\text { work }\end{array}$ & 3.3 & 1390 & $\begin{array}{c}\mathrm{C}_{2} \mathrm{H}_{4}, \\
\mathrm{H}_{2} \mathrm{O}, \mathrm{CH}_{4}\end{array}$ \\
\hline \hline
\end{tabular}

\section{WAVELEnGth SELECtion}

Although benzene has absorption bands in the ultraviolet (UV) wavelength region, the broad features of many other hydrocarbons in UV do not permit interference-free selective measurements. The infrared (IR) absorption spectrum provides opportunities for highly selective detection of benzene and other air pollutants. Based on the IR spectrum of benzene shown in Fig. 1(a), given in the Pacific Northwest National Laboratory (PNNL) database [31], it is obvious that the best wavelength to measure benzene is near $674 \mathrm{~cm}^{-1}(14.837 \mu \mathrm{m})$. However, this wavelength region is currently not accessible by commercially available semiconductor lasers. It was mentioned in the Introduction section that benzene measurements near $1038 \mathrm{~cm}^{-1}(9.64 \mu \mathrm{m})$ [25] and $3090 \mathrm{~cm}^{-1}$ $(3.4 \mu \mathrm{m})$ [28] might lead to errors due to the interference of ozone and isoprene, respectively. Therefore, we instead selected the vibrational band of benzene near $3040 \mathrm{~cm}^{-1}(3.3$ $\mu \mathrm{m})$, shown in Fig. 1(b), which has negligible ozone and isoprene interference. However, this region can have some interference from ethylene and methane. Fig. 2 shows simulated absorbance of benzene, ethylene, methane, isoprene, ozone and water vapor at room conditions $\left(\mathrm{T}=25{ }^{\circ} \mathrm{C}, \mathrm{P}=1\right.$ atm, $\mathrm{RH}=45 \%$ ) near the selected wavelength region the two previous benzene sensors and this work. In Fig. 2(a), near $1038 \mathrm{~cm}^{-1}$ [25], significant interference occurs from ozone, ethylene and water vapor, thus leading to false concentration readings of benzene in the presence of these species. In Fig. 2(b), near $3090 \mathrm{~cm}^{-1}$ [28], isoprene, ethylene and water vapor have high interference which would result in over-estimated benzene concentrations. Although benzene has narrowband spectral features at sub-atmospheric pressures which helps in minimizing water interference; however, interference caused by isoprene and ethylene cannot be avoided as such. The selected region for this work, near $3040 \mathrm{~cm}^{-1}$, shown in Fig. 2(c), has interference from ethylene, methane and water vapor. A multi-dimensional linear regression (MLR) algorithm, discussed in section 4, is implemented to measure benzene in the presence of these interfering species. This region, however, is insensitive to the presence of acetone, ammonia, nitrous oxide, carbonyl sulfide, formic acid, nitrogen dioxide and nitric acid [31, 32]. 
(a)

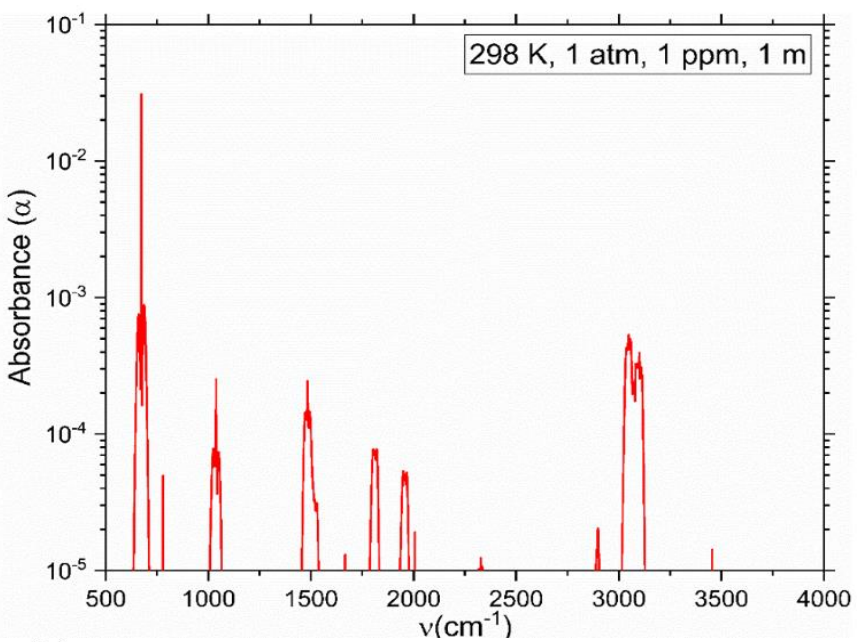

(b)

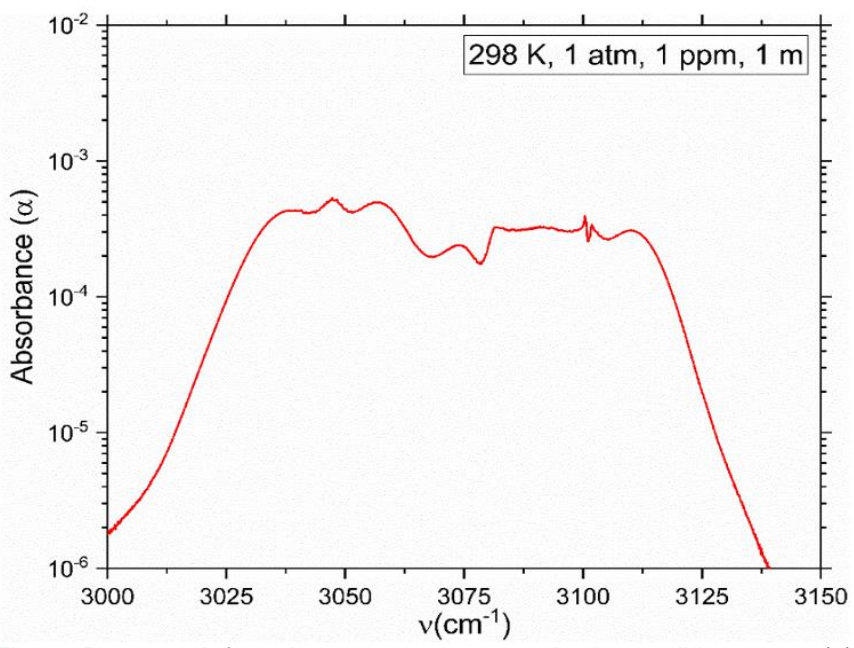

Fig. 1. Benzene infrared spectrum at atmospheric conditions over (a) $500-4000 \mathrm{~cm}^{-1}$, (b) $3000-3150 \mathrm{~cm}^{-1}$. Spectral data from PNNL database [31].

(a)

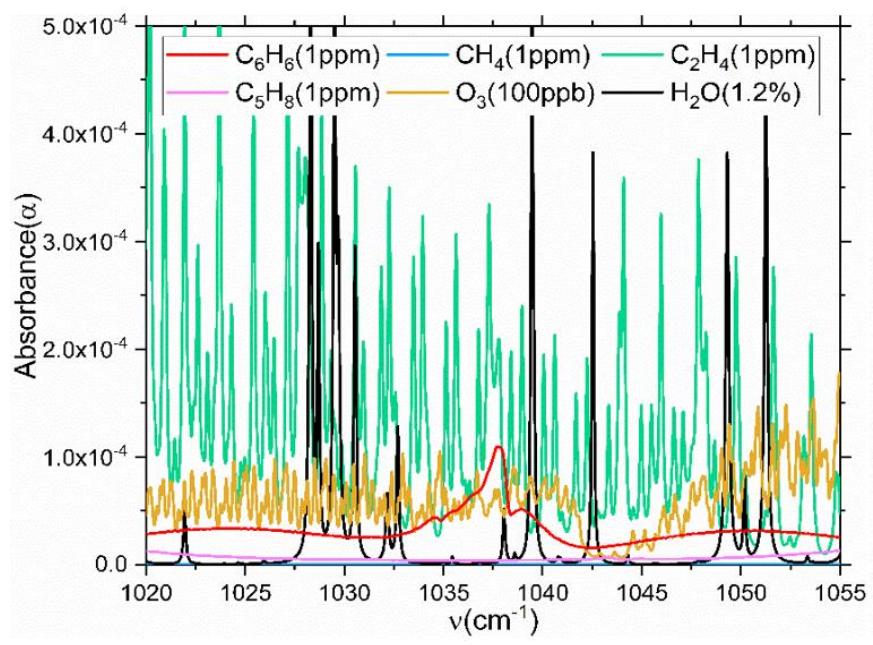

(b)

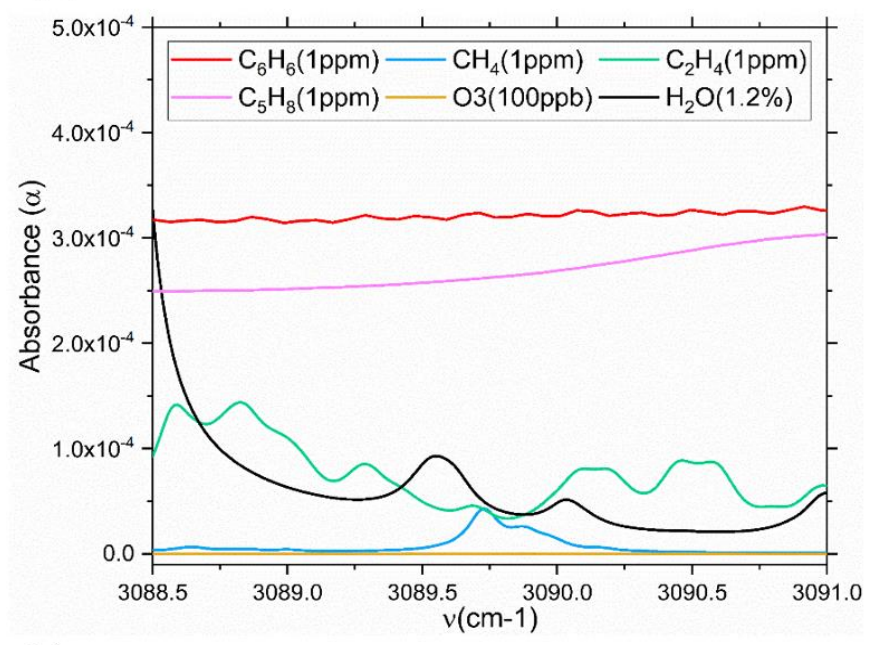

(c)

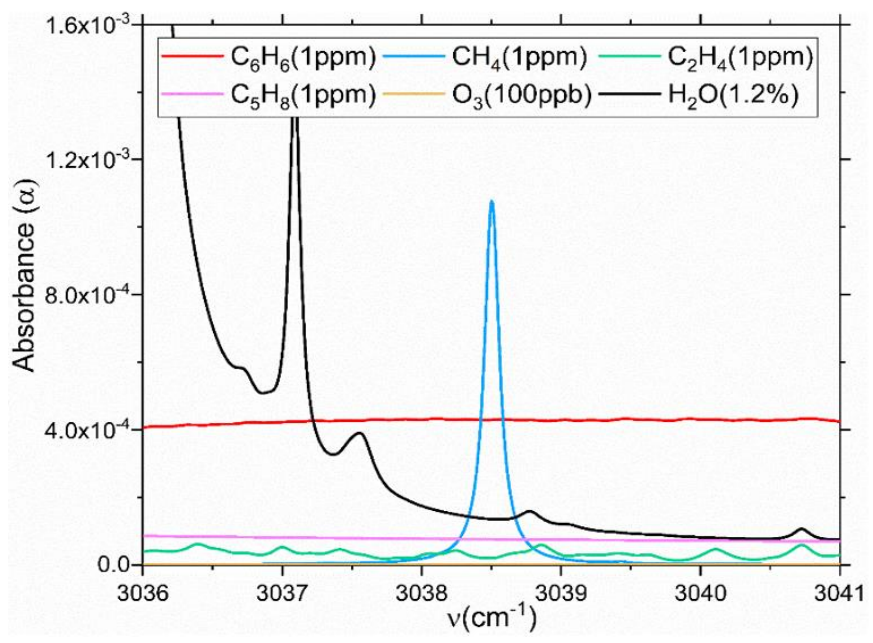

Fig. 2. Benzene, methane, ethylene, isoprene, ozone and water vapor spectra at $\mathrm{T}=298 \mathrm{~K}, \mathrm{P}=1 \mathrm{~atm}, \mathrm{~L}=1 \mathrm{~m}$ over (a) $1020-1055 \mathrm{~cm}^{-1}$, (b) $3088.3-3091 \mathrm{~cm}^{-1}$, (c) $3036-3041 \mathrm{~cm}^{-1}$. Spectral data from PNNL [31] and HITRAN [32] databases.

\section{ABSORPTION PRINCIPLES}

The principle of laser absorption spectroscopy relates the laser intensity to the gas properties via Beer-Lambert Law [33]:

$$
A_{S P}=\ln \left(\frac{I_{0}}{I_{t}}\right)=S(\mathrm{~T}) \mathrm{P} \chi L \phi(v)
$$

In this relation, $A_{S P}$ is the measured absorbance for a single pass of the laser, $I_{0}$ and $I_{t}$ are the incident and transmitted laser intensities, $S(T)$ is the temperature-dependent linestrength, $P$ is the total pressure of the gas mixture, $\chi$ is the gas mole fraction (absorbing species), $L$ is the absorption path-length travelled by the laser (length of the sampling cell in this work) and $\phi(v)$ is the frequency-dependent line-shape function. For a given absorption transition and experimental conditions $(v, T, P)$, smaller values of mole fraction $(\chi)$ can only be measured by increasing the path-length, $L$ [34]. One effective methodology for increasing $L$ utilizes two 
highly reflective parallel concave mirrors to create an optical cavity through multiple reflections of the laser light.

Cavity-based absorption techniques, particularly cavity ringdown spectroscopy (CRDS) and cavity enhanced absorption spectroscopy (CEAS), are making a significant contribution towards the detection of highly diluted species in the gaseous phase [35]. Although both techniques observe the light intensity exiting the cavity, their operating principles are quite different [36]. In CRDS, light intensity builds up inside the cavity and then its characteristic exponential decay time is measured [37]. In CEAS, rapid frequency scanning over a spectral range results in observing spectrally-resolved absorption features [38]. Here, the output intensity from the cavity is characterized by losses due to the mirror transmission/absorption and the absorption of the target gas.

Thus, the cavity absorbance, $A_{C E A S}$, is related to an equivalent single-pass absorbance, $A_{S P}$, via (2) [39] which is valid for all $A_{S P}$ and $R$ :

$$
A_{S P}=-\ln \left(1-\frac{e^{A_{C E A S}}-1}{G}\right)
$$

Here, $G$ is the gain factor of the cavity which is derived from the mirrors' reflectivity via (3):

$$
G=\frac{R}{1-R}
$$

In the weak absorption and high reflectivity limit $\left(A_{S P} \rightarrow 0\right.$ and $R \rightarrow 1$ ), (2) simplifies to:

$$
A_{S P}=\frac{e^{A_{C E A S}}-1}{G}
$$

In this work, (2) was used for all measurements. After calculating $A_{S P}$ it is then used in the Beer-Lambert relation (1) to calculate the corresponding species mole fraction.

\section{Multidimensional Linear Regression}

The proposed benzene sensor is based on scanned-wavelength absorption spectroscopy, where the laser wavelength is current-tuned (at a repetition frequency of $1 \mathrm{kHz}$ ) over $3036 \sim$ $3041 \mathrm{~cm}^{-1}$. Since the spectra of benzene, ethylene, methane and water vapor overlap in the selected frequency range, a multidimensional-linear regression (MLR) algorithm is applied. The measured spectrum is considered to be a linear combination of four reference spectra of the absorbing species [40]:

$$
y_{i}=a_{0}+\sum_{k=1}^{4} a_{k} x_{k i}
$$

Here, $y_{i}$ is the $i$ th data point of the measured absorption, $a_{k}$ is the contribution of each absorbing component to the spectrum, $k=1,2,3,4$ corresponds to $\mathrm{C}_{6} \mathrm{H}_{6}, \mathrm{C}_{2} \mathrm{H}_{4}, \mathrm{CH}_{4}$ and $\mathrm{H}_{2} \mathrm{O}, x_{k i}$ is the intensity of the $k$ th reference spectrum at the frequency of the $i$ th data point, and $a_{0}$ is an offset which is set to zero. We performed MLR fitting to the measured data using MATLAB to find the best-fitting 3D hyperplane as described by (5).

\section{SENSOR SETUP}

The sensor uses a distributed feedback interband cascade laser (DFB-ICL, Nanoplus) emitting near $3.3 \mu \mathrm{m}$ with an output power $\sim 2 \mathrm{~mW}$. Higher power commercial lasers are not available in this region. A $670 \mathrm{~nm}$ red laser (Thorlabs) was propagated collinearly with the IR laser to facilitate optical alignment. Two ZnSe mirrors of $99.97 \%$ nominal reflectivity (LohnStar Optics) were used to form a cavity in a $50 \mathrm{~cm}$ sampling cell. The laser was aligned in an off-axis cavity which suppressed the spurious coupling noise significantly compared to an on-axis cavity. The high mirror reflectivity, along with the low laser power, made the alignment and measurements highly challenging as the transmitted laser intensity was very weak. The transmitted signal was collected via a focusing lens on to a $1.5 \mathrm{MHz}$ AC-coupled, TE-cooled photodetector (Vigo Systems). Optical schematic of this sensor is shown in Fig. 3.

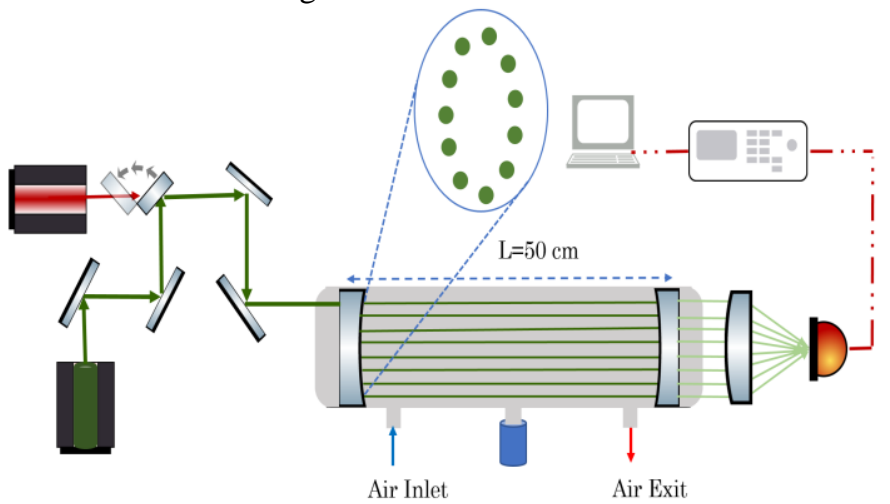

Fig. 3. Optical schematic of the benzene sensor.

\section{A. Integration Time}

Allan deviation may be calculated for sensor systems to characterize their long-term stability. The Allan deviation plot of the signal intensity for the benzene sensor setup is shown in Fig. 4. At early times of the measurement, thermal (Johnson) noise is dominant and thus the deviation decreases following a $1 / \sqrt{t}$ trend [41]. The small hump that appears (at $\sim 3 \mathrm{~s}$ ) can be attributed to residual etalon effects in the optical setup [42]. At longer integration times, Allan deviation increases due to laser intensity fluctuations when operating at the resonance wavelength [43]. Therefore, the optimum integration time for this sensor system is 6 seconds. 


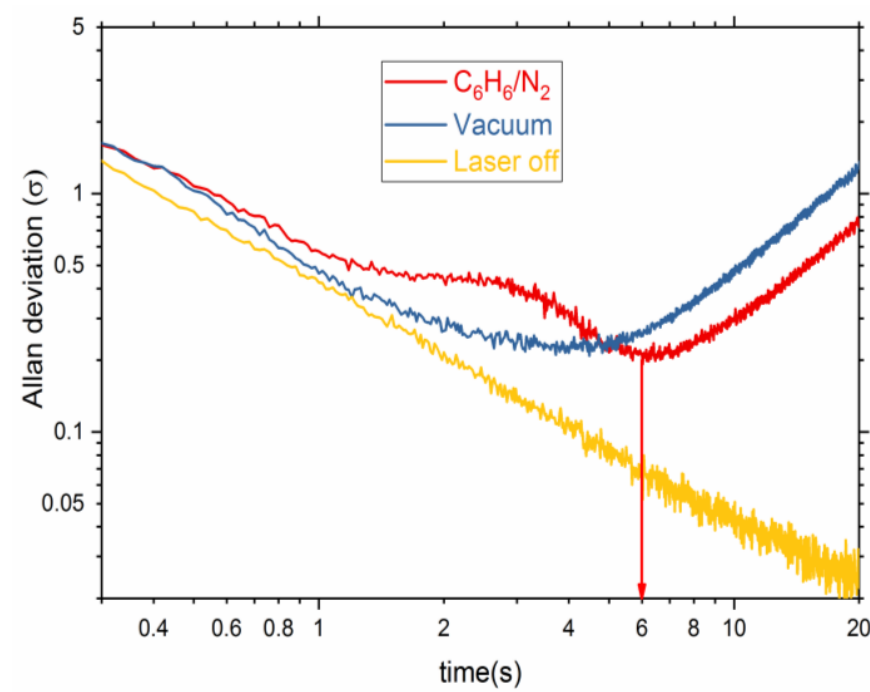

Fig. 4. Allan deviation plot of the benzene sensor. Optimal integration time is 6 seconds.

\section{B. Reflectivity Measurement}

Alquaity et al. [44] have reported that the mirror reflectivity can deviate significantly from the manufacturer's nominal specification, resulting in an unacceptably large uncertainty in the cavity measurements. Therefore, precise value of the reflectivity should be determined experimentally [39]. We performed calibration experiments for $R$ using various mixtures of $\mathrm{C}_{6} \mathrm{H}_{6} / \mathrm{N}_{2}$ with known compositions. The reflectivity was found by measuring $A_{C E A S}$ and using simulated $A_{S P}$ from PNNL database [31] in (2). Based on several experiments at various benzene concentrations (see Fig. 5), reflectivity was determined to be $R=99.964 \pm 0.002 \%$, which is within $0.01 \%$ of the nominal reflectivity specified by the manufacturer. The uncertainty $( \pm 0.002 \%)$ was determined based on a $95 \%$ confidence interval of the measured values. The reflectivity of $R=99.964 \%$ increases the effective path-length of the sensor from $50 \mathrm{~cm}$ to $1.39 \mathrm{~km}$. The mirrors' reflectivity may be affected due to contamination on the mirrors, which can be reduced by adding an air filter to the cell inlet, and accounted for by periodic calibration with known $\mathrm{C}_{6} \mathrm{H}_{6} / \mathrm{N}_{2}$ mixtures. Mirror reflectivity may be calibrated rather easily by measuring the ringdown time of an empty cavity, as described in detail previously [45]. In the absence of absorbing species, the following equation may be used to determine mirror reflectivity:

$$
\tau_{0}=\frac{L}{c(1-R)}
$$

Here, $\tau_{0}$ is the time needed for the light intensity to fall to $1 / e$ of its initial value, $L$ is the length of the cavity, $c$ is the speed of light and $R$ is the mirrors' reflectivity.

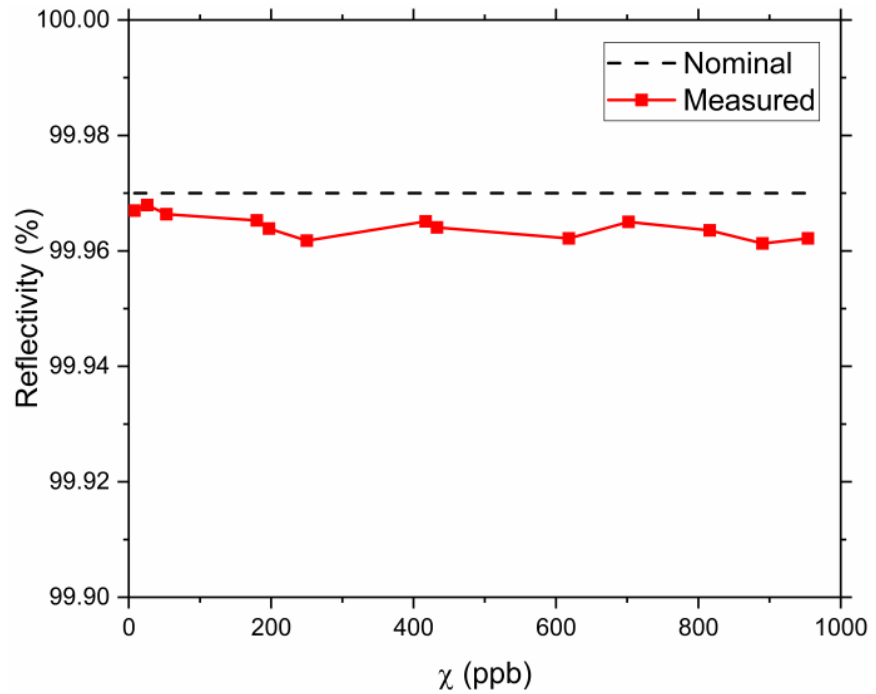

Fig. 5. Mirrors' reflectivity measurements at varying concentrations of benzene in $\mathrm{N}_{2}\left(T=295 \mathrm{~K}, \mathrm{P}_{\text {total }}=1 \mathrm{~atm}\right)$.

\section{Free Spectral Range}

The nominal laser spot size for the cavity may be calculated by (8) [46]:

$$
s=\sqrt{\frac{2 \lambda L}{\pi \ln 2} \sqrt{\frac{2 R^{2}}{L\left(R-\frac{L}{2}\right)}}}=1.87 \mathrm{bmm}
$$

Although the cavity mirrors had a diameter of $25 \mathrm{~mm}$, the exposed diameter of the mirrors was limited to about $8 \mathrm{~mm}$ due to the geometry of the mirror mounts. Therefore, the Lissajous circular spot pattern was aligned within a diameter of about $6 \mathrm{~mm}$ to avoid light clipping near the edges of the mounts. This results in a circumference of about $19 \mathrm{~mm}$ which would fit about 10 non-overlapping laser spots. Assuming a refractive index of unity in air, the effective free spectral range ( FS $\mathrm{R}_{\mathrm{e} f f}$ ) is calculated via (8) [46]:

$$
F S \mathrm{R}_{\text {eff }}=\frac{c}{2 n L}
$$

Here, $c$ is the speed of light in air, $n$ is the number of nonoverlapping spots, and $L$ is the length of the sampling cell. The number of these spots in an on-axis alignment is 1, resulting in an $F S \mathrm{R}_{\mathrm{e} f f}=3000 \mathrm{MHz}$, which is reduced to $300 \mathrm{MHz}$ due to the 10 non-overlapping spots in the off-axis alignment. The cavity coupling noise is thus reduced due to the lower $F S \mathrm{R}_{\text {eff }}$ which increases the density of the cavity mode structure within the same spectral frequency [47].

\section{EXPERIMENTAL RESULTS}

\section{A. Benzene / Nitrogen Measurements}

Measurements were performed with various mixtures of benzene in nitrogen. Fig. 6(a) compares measured absorbance $\left(A_{C E A S}\right)$, for an 8 ppb $\mathrm{C}_{6} \mathrm{H}_{6} / \mathrm{N}_{2}$ mixture, to the simulated single-pass absorbance $\left(A_{S P}\right)$. As expected, the cavity results in more than 3 orders of magnitude enhancement in the 
absorption signal. A number of $\mathrm{C}_{6} \mathrm{H}_{6} / \mathrm{N}_{2}$ mixtures were prepared with known mole fractions ranging from $8 \mathrm{ppb}$ to $2.43 \mathrm{ppm}$ to test the sensor performance, and the resulting data are shown in Fig. 6(b). Benzene detection limit (in $\mathrm{C}_{6} \mathrm{H}_{6} / \mathrm{N}_{2}$ mixtures) was determined to be $200 \mathrm{ppt}$ by extrapolating the measured data to a signal-to-noise-ratio (SNR) of unity.

(a)

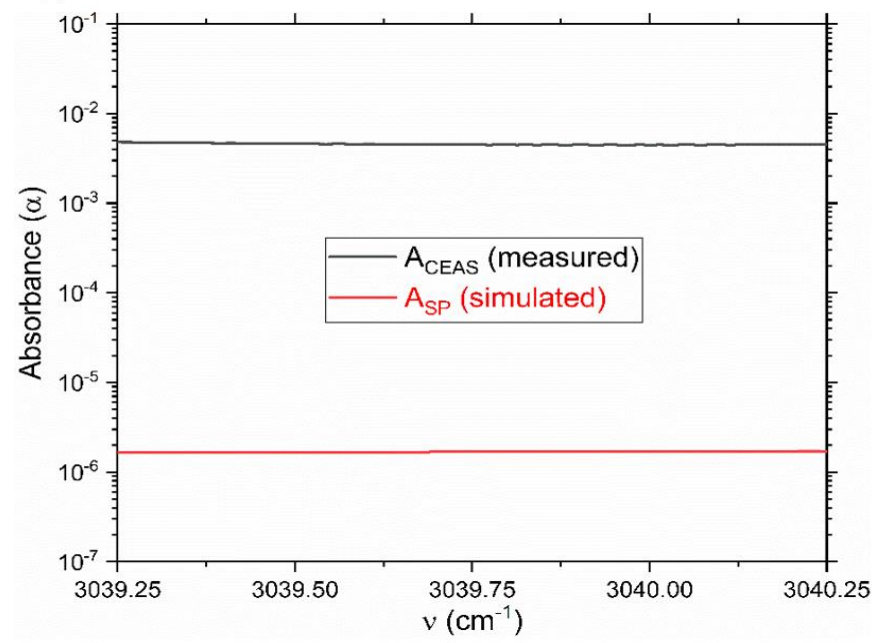

(b)

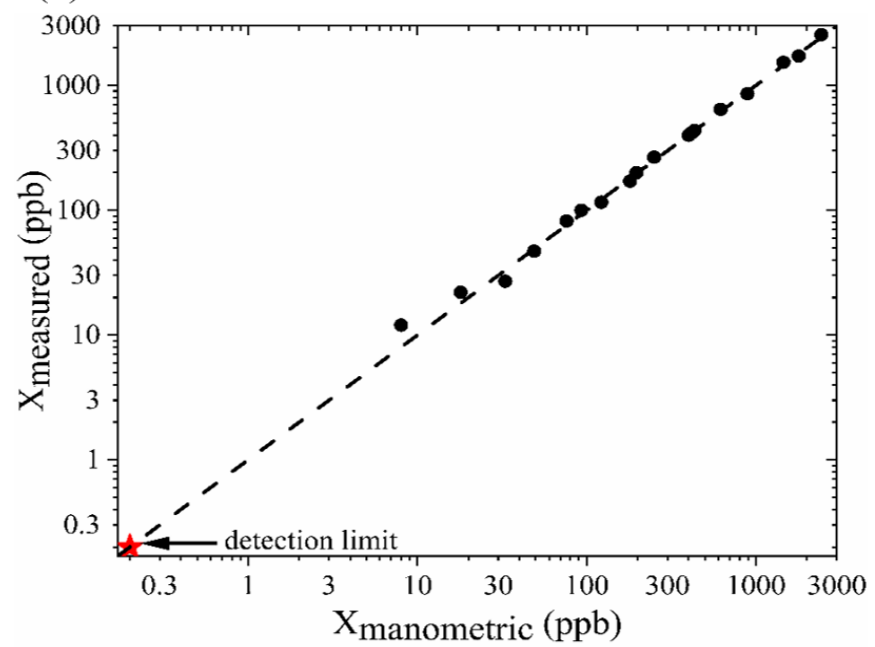

Fig. 6. (a) Comparison of measured cavity absorbance ( $A_{C E A S}$ ) with simulated single-pass absorbance $\left(\mathrm{A}_{\mathrm{SP}}\right)$ for $\chi=8 \mathrm{ppb} \mathrm{C}_{6} \mathrm{H}_{6}$ in $\mathrm{N}_{2}, \mathrm{~T}=$ $298 \mathrm{~K}, \mathrm{P}=1 \mathrm{~atm}, \mathrm{~L}=50 \mathrm{~cm}$, (b) Measured benzene mole fraction versus manometrically calculated mole fraction.

\section{B. Multi-species Measurements}

Gas samples with known concentrations of benzene, ethylene, methane and water vapor in nitrogen were prepared

TABLE II

ERRors in SimULtaneous MEASUREMENTS OF BENZENE, ETHYLENE, Methane AND WATER VAPOR AT ROOM CONDITIONS. THE ERRORS ARE CALCULATED FROM MEASUREMENTS ON 10 MIXTURES WITH VARYING MOLE FRACTIONS OF CONSTITUENTS

\begin{tabular}{ccccc}
\hline \hline & Benzene & Ethylene & Methane & $\begin{array}{c}\text { Water } \\
\text { Vapor }\end{array}$ \\
\hline Mean Error (\%) & 4.1 & 21.6 & 2.2 & 7.8 \\
\hline $\begin{array}{c}\text { Error standard } \\
\text { deviation (\%) }\end{array}$ & 2.9 & 16.9 & 2.9 & 8.6 \\
\hline \hline
\end{tabular}

to test the sensor performance for benzene measurements in the presence of interfering species. MLR (multi-linear regression) was applied using the reference spectra (shown in Fig. 2) to measure the concentration of each species. The minimum detection limit of benzene increased from $200 \mathrm{ppt}$ $\left(\mathrm{C}_{6} \mathrm{H}_{6} / \mathrm{N}_{2}\right.$ mixtures) to $2 \mathrm{ppb}$ (multi-species mixtures) due to the overlapping resolved spectra of ethylene, methane and water vapor. The details are discussed in the next section. For error quantification, 10 mixtures with known concentrations of benzene, ethylene, methane and water vapor were prepared and the results were analyzed. In these mixtures, benzene concentration was varied from 100 to $1000 \mathrm{ppb}$, ethylene concentration from 100 to $1500 \mathrm{ppb}$, methane concentration from 300 to $1000 \mathrm{ppb}$, and water vapor concentration from 0.3 to $1.2 \%$. The relative error between the measured and the manometric concentration was calculated for each mixture. The mean and standard deviation of these relative errors are shown in Table II. These results indicate that we can successfully measure benzene in the presence of interfering species and the sensor can be applied for detecting benzene in real air samples. Note that the large error on ethylene measurements is due to its weak absorption spectrum compared to benzene.

\section{Minimum Detection Limit}

One of the most important parameters in trace gas sensors is the measurement sensitivity, which is expressed in terms of the minimum detection limit [48]. This can be determined from the Allan deviation of the absorbance signal which gave a minimum absorbance of $0.044 \%$ corresponding to a detection limit of $~ 900$ ppt. However, a more reasonable value of detection limit may be determined from the signal-tonoise-ratio (SNR) of the measured signal, corresponding to an $\mathrm{SNR}=1$. The fluctuation of the detected signal is a direct indication of the signal noise. These fluctuations arise from various sources, such as white noise including the Johnson noise coming from the detector and/or the laser source, background noise arising from optical components including optical interference / reflection, and mechanical oscillations. In the case of multiple reflection schemes applied in long path-length absorption spectroscopy, optical noise is the dominant factor for ultra-sensitivity. Fig. 7 shows a measured absorption signal of a mixture containing $362 \mathrm{ppb}$ of benzene, $636 \mathrm{ppb}$ of ethylene and $318 \mathrm{ppb}$ of methane. An absorption peak is observed at $3038.49 \mathrm{~cm}^{-1}$ due to methane absorption, while the broad wing is due to the non-resolved spectra of benzene and ethylene. The relatively flat spectral range from $3037.95-3038.05 \mathrm{~cm}^{-1}$ is selected here to quantify the noise, as shown in the inset of Fig. 7. Calculations show that an SNR $=1$ corresponds to an absorption of $0.1 \%$ which occurs due to signal fluctuations (or noise). Equation 2 is then used to convert this absorption to a minimum detection limit of $\sim 2$ ppb. 


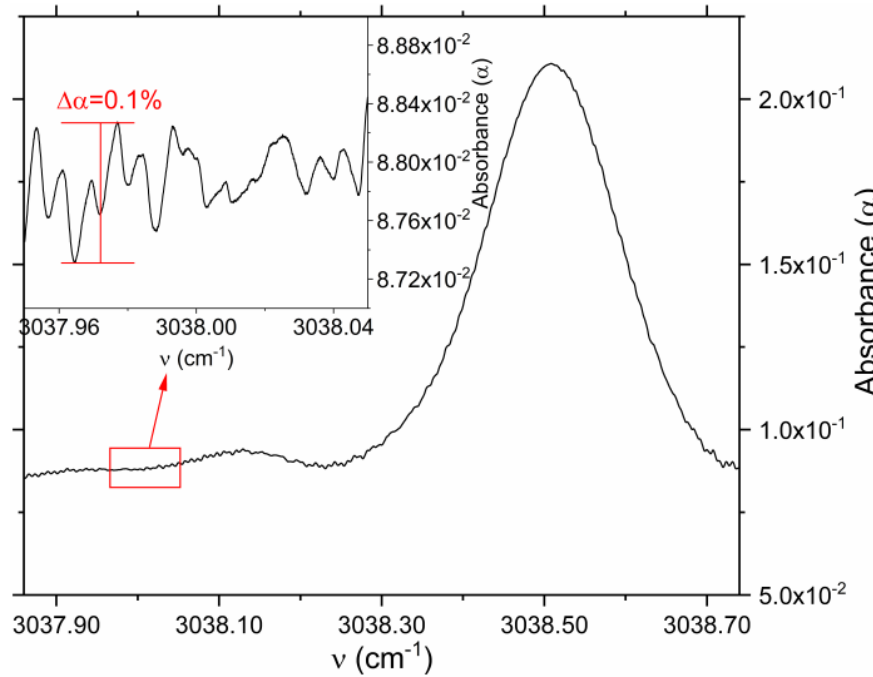

Fig. 7. Measured absorption signal of a mixture of $362 \mathrm{ppb}$ of benzene, $636 \mathrm{ppb}$ of ethylene and $318 \mathrm{ppb}$ of methane in nitrogen $(\mathrm{T}=$ $298 \mathrm{~K}, \mathrm{P}=1 \mathrm{~atm})$.

\section{Cross-Sensitivity Analysis}

The sensitivity and dynamic range of all sensors are limited by cross sensitivities to species other than the intended measurand [49]. Here, two approaches are applied to carry out cross-sensitivity analysis. First, we investigate that each species is measured accurately within the targeted range in the presence of other interfering species. Second, we study how the variation in the concentrations of ethylene, methane and water could affect the uncertainty of the measured benzene concentration. As the samples for calibrating and validating the sensor had random concentrations of benzene, ethylene, methane and water vapor, these mixtures cannot be applied for a cross sensitivity analysis. Instead, simulated spectra are used here to do cross-sensitivity analysis [50]. Details of the crosssensitivity analysis are provided in the Appendix.

To simulate the spectra, concentrations of benzene, ethylene and methane are varied from 100 to $1000 \mathrm{pbb}$ in 20 equal steps, while that of water is varied from 0.8 to $2.2 \%$ in 20 equal steps. A Gaussian White noise was added to the simulated absorbance with an $\mathrm{SNR}=15$, which corresponds to the ratio of the summed squared magnitude of absorbance to that of the noise, in decibels. The resulting errors in the regression show good agreement with Section 7.2, indicating that the simulated spectra are a good representative of experimental measurements.

In Fig. 8, the concentration of the targeted species is varied within the aforementioned range and then its concentration is calculated by MLR while keeping the concentrations of the rest of the species fixed at the middle of their corresponding ranges (e.g., In Fig. 8(a), benzene concentration was varied from 100 to $1000 \mathrm{ppb}$ while fixing ethylene and methane at $450 \mathrm{ppb}$ of and water vapor at $1.5 \%$ ). MLR was applied to the cumulative simulated absorbance spectra at $\mathrm{T}=25^{\circ} \mathrm{C}, \mathrm{P}=1$ atm, and $\mathrm{L}=13.9 \mathrm{~km}[31,32]$. The error is higher for ethylene than other species since its reference absorbance is weak compared to other species (see Fig. 2(c)).

As benzene is our main measurand, the effect of varying the concentration of each species on benzene concentration uncertainty was also examined. As shown in Fig. 9, the concentration of benzene was fixed at a certain amount while one of the other interfering species was varied within the targeted range (e.g., In Fig. 9, the green color refers to a fixed concentration of benzene at $400 \mathrm{ppb}$ while varying ethylene concentration in the range of $100-1000 \mathrm{ppb}$; methane and water were fixed at $500 \mathrm{ppb}$ and $1.2 \%$, respectively). For better visualization, the benzene concentration was fixed at 400,500 and $600 \mathrm{ppb}$ in the cases of varying ethylene, methane and water, respectively. It is seen that benzene concentration can be determined with an acceptable error $(<$ $10 \%)$ in the presence of interfering species within their specified ranges.
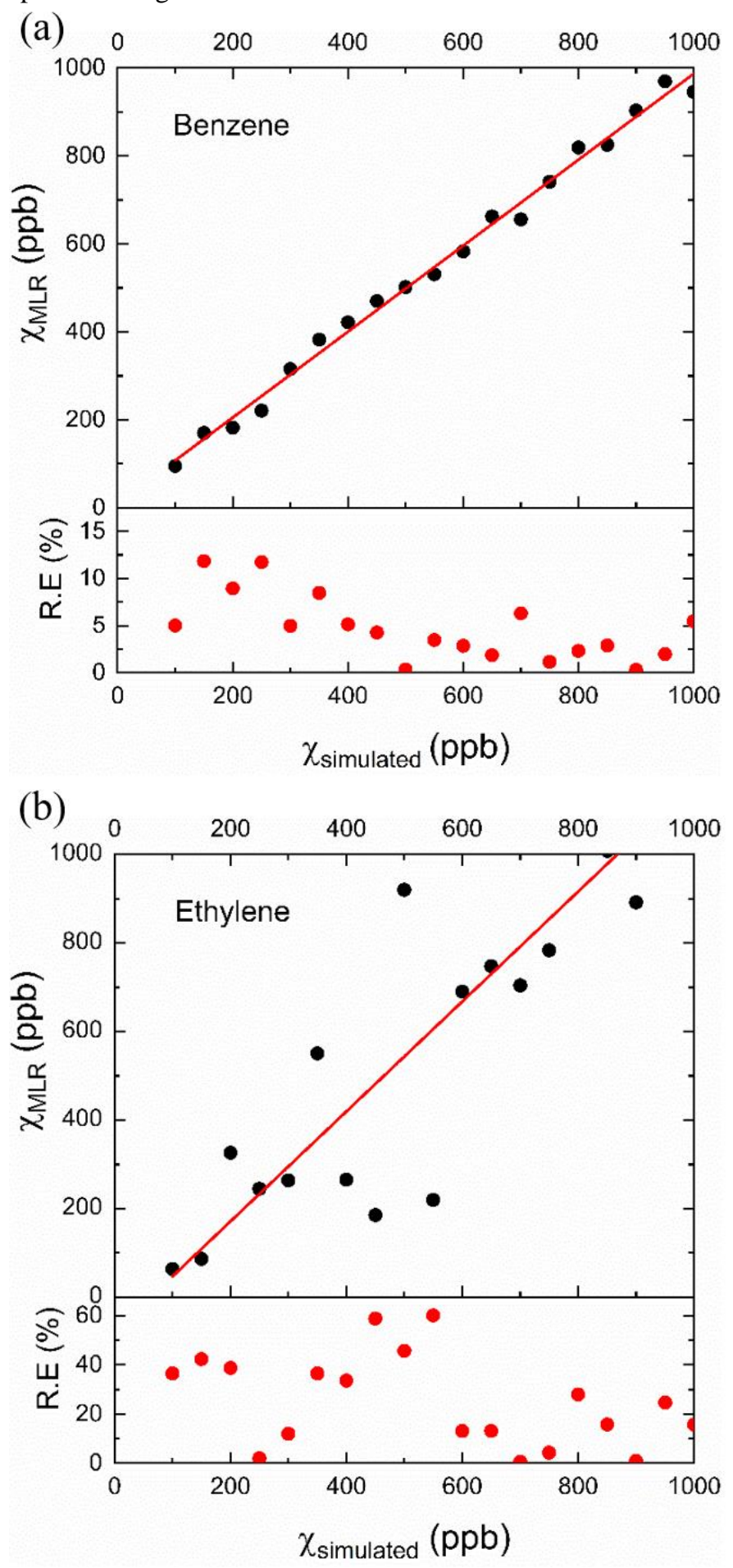

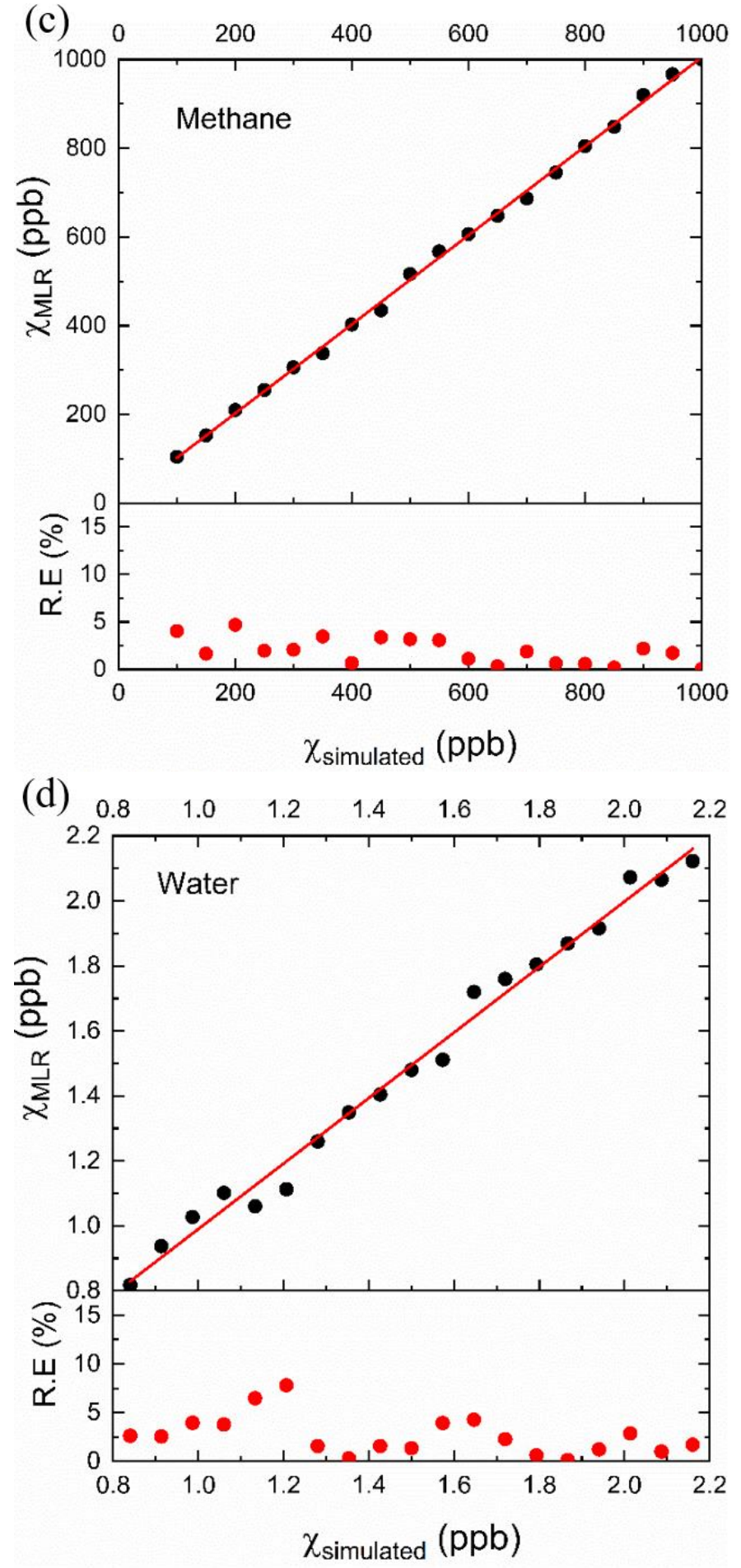

Fig. 8. Concentrations of (a) Benzene, (b) Ethylene, (c) Methane, (d) Water vapor obtained by MLR applied to cumulative simulated spectra with an SNR of 15 . Also plotted are \% relative errors compared to the known values. While varying the concentration of one species in the respective panels, others were fixed at $500 \mathrm{ppb}$ (benzene, ethylene, methane) and $1.2 \%$ (water vapor).

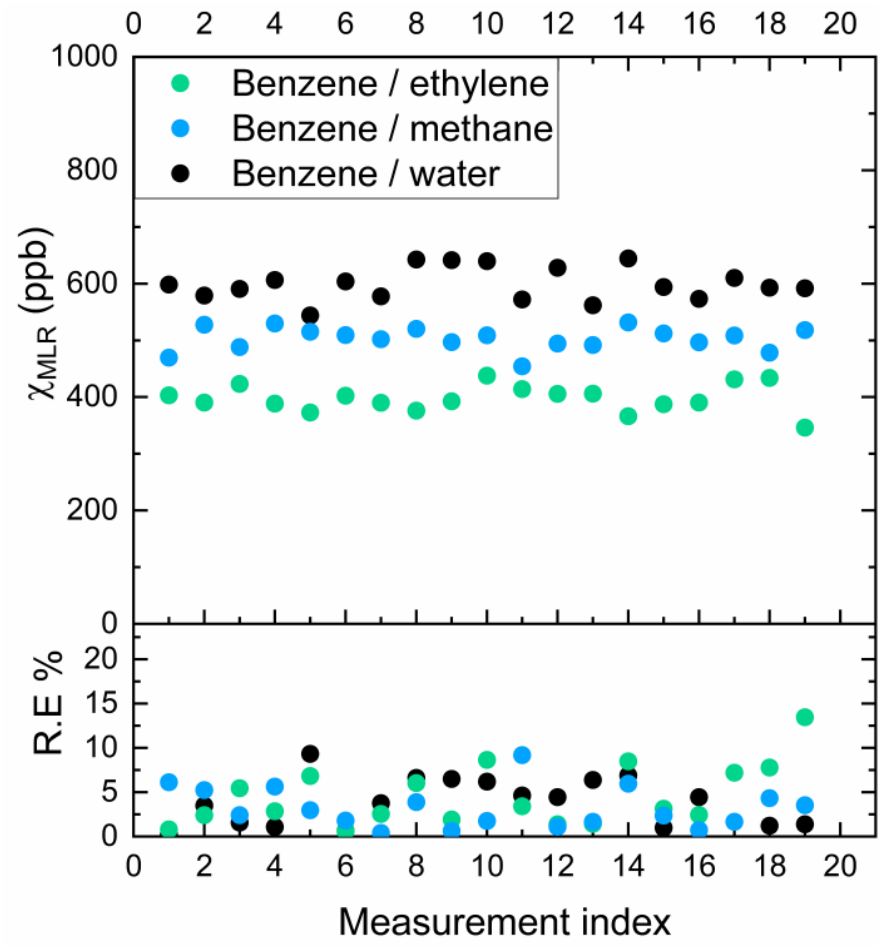

Fig. 9. Benzene concentration and $\%$ relative error obtained by applying MLR to simulated spectra. Green: $\chi_{\text {Benzene }}=400 \mathrm{ppb}, \chi_{\text {Methane }}=$ $500 \mathrm{ppb}, \chi$ Water $=1.2 \%$ while ethylene was varied from 100 to $1000 \mathrm{ppb}$ in 20 equal steps. Blue: $\chi_{\text {Benzene }}=500 \mathrm{ppb}, \chi_{\text {Ethylene }}=500 \mathrm{ppb}, \chi_{\text {Water }}=$ $1.2 \%$ while methane was varied from 100 to $1000 \mathrm{ppb}$ in 20 equal steps. Black: $\chi_{\text {Benzene }}=600 \mathrm{ppb}, \chi_{\text {Ethylene }}=500 \mathrm{ppb}, \chi_{\text {Methane }}=500 \mathrm{ppb}$ while water was varied from 0.8 to $2.2 \%$ in 20 equal steps.

\section{E. Air Sample Measurements}

Air samples were collected from various locations and measured with the laser sensor; results are listed in Fig. 10. As expected, the benzene concentration in the parking garage was higher on a weekday than on a weekend due to the larger number of vehicles on weekdays. The parking garage likely contains high benzene concentration due to the cold start of vehicles resulting in large amounts of unburnt gasoline in the exhaust. Benzene concentration was the highest at the gasoline service station.

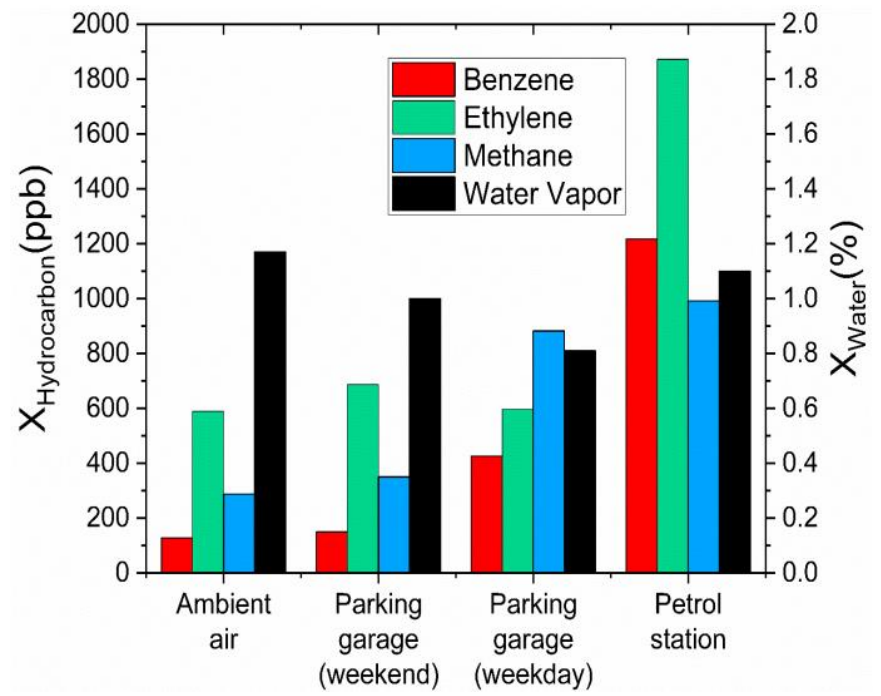

Fig. 10. Measured concentrations of benzene, ethylene, methane and water vapor in the collected samples. 
Laser-based benzene measurements were compared with a gas chromatograph (GC). Fig. 11 shows good agreement between the laser sensor and GC. At low concentrations, the GC showed larger variation for repeated measurements while the laser-based sensor showed very good repeatability. Another advantage of the laser-based sensor is that the total measurement time of the sample is less than 1 minute, while it takes about 10 minutes to do one GC measurement due to the relatively long retention time of benzene [51].

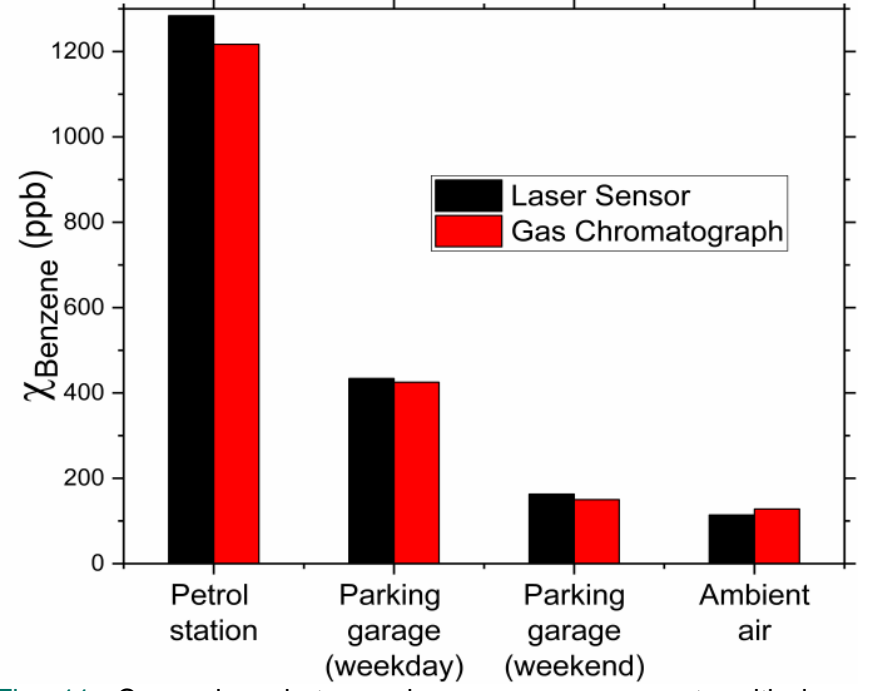

Fig. 11. Comparison between benzene measurements with laserbased sensor and a GC for various air samples.

\section{CONCLUSIONS}

A laser sensor based on cavity enhanced absorption spectroscopy has been developed to measure trace concentrations of benzene. The single-pass absorption increased by three orders of magnitude due to the high reflectivity of the mirrors, thus enabling benzene detection down to $2 \mathrm{ppb}$ in the presence of interfering species. This detection limit is obtained at the optimum integration time of 6 seconds. Multidimensional linear regression was applied to enable simultaneous measurements of benzene, ethylene, methane and water vapor. The sensor was validated with a gas chromatograph and can be applied to monitor air quality in petrochemical facilities where the emissions of these species are high compared to other VOCs, and near residential and industrial areas to monitor indoor air pollution.

\section{APPENDIX: CROSS-SENSITIVITY ANALYSIS}

A multidimensional-linear regression (MLR) algorithm is applied to determine the concentration of the different gases in the mixture. The measured total absorbance spectrum is considered to be a linear combination of four reference spectra of the absorbing species [40]

$$
y_{i}=a_{0}+\sum_{k=1}^{4} a_{k} x_{k i}
$$

Here, $y_{i}$ is the $i$ th data point of the measured absorption, $a_{k}$ is the contribution of each absorbing component to the spectrum, $k=1,2,3,4$ corresponds to $\mathrm{C}_{6} \mathrm{H}_{6}, \mathrm{C}_{2} \mathrm{H}_{4}, \mathrm{CH}_{4}$ and $\mathrm{H}_{2} \mathrm{O}, x_{k i}$ is the intensity of the $k$ th reference spectrum at the frequency of the $i$ th data point, and $a_{0}$ is an offset which is set to zero. We performed MLR fitting to the measured data using MATLAB to get the coefficients. In vector form, the equation goes as:

$$
\begin{aligned}
\left(\begin{array}{c}
y_{1} \\
y_{2} \\
\vdots \\
y_{n}
\end{array}\right) & =a_{\text {benzene }}\left(\begin{array}{c}
x_{\text {benzene }, 1} \\
x_{\text {benzene }, 2} \\
\vdots \\
x_{\text {benzene, } n}
\end{array}\right)+a_{\text {ethylene }}\left(\begin{array}{c}
x_{\text {ethylene }, 1} \\
x_{\text {ethylene }, 2} \\
\vdots \\
x_{\text {ethylene }, n}
\end{array}\right) \\
& +a_{\text {methane }}\left(\begin{array}{c}
x_{\text {methane }, 1} \\
x_{\text {methane }, 2} \\
\vdots \\
x_{\text {methane }, n}
\end{array}\right)+a_{\text {water }}\left(\begin{array}{c}
x_{\text {water }, 1} \\
x_{\text {water }, 2} \\
\vdots \\
x_{\text {water }, n}
\end{array}\right)
\end{aligned}
$$

In matrix form, we solve the system:

$$
\left(\begin{array}{c|cccc}
y_{1} & x_{\text {benzene, } 1} & x_{\text {ethylene }, 1} & x_{\text {methane, } 1} & x_{\text {water }, 1} \\
y_{2} & x_{\text {benzene, } 2} & x_{\text {ethylene, } 2} & x_{\text {methane }, 2} & x_{\text {water }, 2} \\
\vdots & \vdots & \vdots & \vdots & \vdots \\
y_{n} & x_{\text {benzene, } n} & x_{\text {ethylene, } n} & x_{\text {methane, } n} & x_{\text {water }, n}
\end{array}\right)
$$

which has the simple form of $B=A x$.

Note that the system of equations is not exact as the number of equations, $\mathrm{n}$, is more than the number of unknowns, 4 , so we solve for the least squares of this problem instead of the exact solution. The least squares solution provides the contribution of each species, $a_{k}$, coming from each reference vector, $x_{k i}$, to the total measured vector, $y_{i}$. For example, suppose that the reference spectrum of benzene is obtained from PNNL Database at $1 \mathrm{ppm}$ [31], and the reference spectra of ethylene, methane and water vapor are obtained from HITRAN Database at $1 \mathrm{ppm}, 1 \mathrm{ppm}$ and $1 \%$, respectively [32]. If the least squares solution provides the coefficients of [ $\left.\begin{array}{llll}0.5 & 1 & 0.3 & 1.5\end{array}\right]$, this means that the concentrations of benzene, ethylene, methane and water are $0.5 \mathrm{ppm}, 1 \mathrm{ppm}, 0.3 \mathrm{ppm}$ and $1.5 \%$, respectively; and so on.

In Fig. 8(a), we have fixed the concentrations of ethylene, methane and water to $450 \mathrm{ppb}, 450 \mathrm{ppb}$ and $1.2 \%$, respectively. Benzene concentration was varied from 100 to $1000 \mathrm{ppb}$ and calculated using MLR. Benzene calculations are as follows:

$$
\begin{array}{r}
\left(\begin{array}{c}
y_{1} \\
y_{2} \\
\vdots \\
y_{n}
\end{array}\right)=a_{\text {benzene }}\left(\begin{array}{c}
x_{\text {benzene }, 1} \\
x_{\text {benzene }, 2} \\
\vdots \\
x_{\text {benzene }, n}
\end{array}\right)+0.45\left(\begin{array}{c}
x_{\text {ethylene }, 1} \\
x_{\text {ethylene }, 2} \\
\vdots \\
x_{\text {ethylene }, n}
\end{array}\right) \\
+0.45\left(\begin{array}{c}
x_{\text {methane }, 1} \\
x_{\text {methane }, 2} \\
\vdots \\
x_{\text {methane }, n}
\end{array}\right)+1.2\left(\begin{array}{c}
x_{\text {water }, 1} \\
x_{\text {water }, 2} \\
\vdots \\
x_{\text {water }, n}
\end{array}\right)
\end{array}
$$

Here, at each benzene concentration value, which is considered unknown in the algorithm, $y_{i}$ is the overall measured absorbance and $x_{k i}$ are obtained from databases $[31,32]$; thus the only unknown to be obtained is $a_{\text {benzene }}$, which varies from 0.1 to 1 (since benzene is varying from 100 to $1000 \mathrm{ppb}$ with a reference concentration of $1 \mathrm{ppm}$ ). Figure 8(a) shows accurate determination of benzene in the presence of the aforementioned fixed concentrations of ethylene, methane and water. 
The same discussion applies for Figs. 8(b), 8(c) and 8(d) where we determined varying concentrations of ethylene, methane and water, respectively.

In Fig. 9, we check the ability of our system to measure a certain concentration of benzene while varying the concentrations of the interfering species. For the blue color, benzene was fixed to $500 \mathrm{ppb}$ while methane concentration was varied from 100 to $1000 \mathrm{ppb}$. Ethylene and water were fixed at $500 \mathrm{ppb}$ and $1.2 \%$, respectively. Benzene was calculated as:

$$
\begin{array}{r}
\left(\begin{array}{c}
y_{1} \\
y_{2} \\
\vdots \\
y_{n}
\end{array}\right)=a_{\text {benzene }}\left(\begin{array}{c}
x_{\text {benzene, } 1} \\
x_{\text {benzene }, 2} \\
\vdots \\
x_{\text {benzene, } n}
\end{array}\right)+0.5\left(\begin{array}{c}
x_{\text {ethylene }, 1} \\
x_{\text {ethylene }, 2} \\
\vdots \\
x_{\text {ethylene }, n}
\end{array}\right) \\
+a_{\text {methane }}\left(\begin{array}{c}
x_{\text {methane }, 1} \\
x_{\text {methane }, 2} \\
\vdots \\
x_{\text {methane, } n}
\end{array}\right)+1.2\left(\begin{array}{c}
x_{\text {water }, 1} \\
x_{\text {water }, 2} \\
\vdots \\
x_{\text {water }, n}
\end{array}\right)
\end{array}
$$

Here, at each methane concentration value, varied from 100 to $1000 \mathrm{ppb}, y_{i}$ is the overall measured absorbance, $x_{k i}$ are obtained from databases [31, 32], thus the only unknown is $a_{\text {benzene }}$ (here benzene concentration is supposed to be 500 $\mathrm{ppb}$ with a reference concentration of $1 \mathrm{ppm}$ ). Figure 9 shows accurate determination of benzene in the presence of the aforementioned varying methane and fixed ethylene and water concentrations.

The same discussion applies for the green and black colors where we determined fixed concentrations of benzene (at 400 and $600 \mathrm{ppb}$ ) while varying ethylene and water concentrations, respectively.

\section{ACKNOWLEDGMENT}

This work was funded by the Environmental Protection Department (EPD) of Saudi Aramco (RGC/3/3202-01-01).

\section{REFERENCES}

[1] Austin, C. C., et al. "Characterization of volatile organic compounds in smoke at experimental fires." Journal of Toxicology and Environmental Health Part A 63.3 (2001): 191-206.

[2]Wallace, Lance. "Major Sources of Exposure to Benzene and Other Volatile Organic Chemicals 1, 2." Risk Analysis 10.1 (1990): 59-64

[3] Foo, Swee-Cheng. "Benzene pollution from gasoline usage." Science of the Total Environment 103.1 (1991): 19-26.

[4]Helmer, Karl J. "Accumulated Cases of Chronic Benzene Poisoning in the Rubber Industry." Acta Medica Scandinavica 118.4-5 (1944): 354-75.

[5] Greenburg, Leonard, et al. "Benzene (benzol) poisoning in the rotogravure printing industry in New York City." Journal of Industrial Hygiene and Toxicology 21 (1939): 395-420.

[6]Sekar, Abinaya, George K. Varghese, and MK Ravi Varma. "Analysis of benzene air quality standards, monitoring methods and concentrations in indoor and outdoor environment." Heliyon 5.11 (2019): e02918.

[7] Sinha, Sukesh Narayan, et al. "Environmental monitoring of benzene and toluene produced in indoor air due to combustion of solid biomass fuels." Science of the total environment 357.1-3 (2006): 280-287.

[8]Bhattacharya, S. C., and P. Abdul Salam. "Low greenhouse gas biomass options for cooking in the developing countries." Biomass and Bioenergy 22.4 (2002): 305-317.

[9] World Health Organization (WHO). "Exposure to Benzene: A Major Public Health Concern. WHO Document Production Services." (2015).
[10] Abplanalp, Wesley, et al. "Benzene exposure is associated with cardiovascular disease risk." PloS one 12.9 (2017): e0183602.

[11] Robinson, Simon N., et al. "Immunotexicological effects of benzene inhalation in male Sprague-Dawley rats." Toxicology 119.3 (1997): 227 237.

[12] Durmusoglu, Ertan, Fatih Taspinar, and Aykan Karademir. "Health risk assessment of BTEX emissions in the landfill environment." Journal of hazardous materials 176.1-3 (2010): 870-877.

[13] Ravindra, Khaiwal, Ranjeet Sokhi, and Rene Van Grieken. "Atmospheric polycyclic aromatic hydrocarbons: source attribution, emission factors and regulation. " Atmospheric Environment 42.13 (2008): 2895-2921.

[14] Böhringer, Christoph, et al. "Assessing emission regulation in Europe: an interactive simulation approach." The Energy Journal (2005): 1-21.

[15] Yardley-Jones, Anderson, D. Anderson, and D. V. Parke. "The toxicity of benzene and its metabolism and molecular pathology in human risk assessment." Occupational and Environmental Medicine 48.7 (1991): 437-444.

[16] Gohlke, Roland S. "Time-of-flight mass spectrometry and gas-liquid partition chromatography." Analytical Chemistry 31.4 (1959): 535-541.

[17] Sun, Kai, et al. "TDL absorption sensors for gas temperature and concentrations in a high-pressure entrained-flow coal gasifier.

" Proceedings of the Combustion Institute 34.2 (2013): 3593-3601.

[18] Yamazoe, Noboru, Go Sakai, and Kengo Shimanoe. "Oxide semiconductor gas sensors." Catalysis Surveys from Asia 7.1 (2003): $63-$ 75.

[19] Eicker, Hartmut. "Method and apparatus for determining the concentration of one gaseous component in a mixture of gases." U.S. Patent No. 4,012,692. 15 Mar. 1977.

[20] Dirksen, James A., Kristin Duval, and Terry A. Ring. "NiO thin-film formaldehyde gas sensor." Sensors and Actuators B: Chemical 80.2 (2001): 106-115.

[21] Pohanka, Miroslav, and Petr Skládal. "Electrochemical biosensors-principles and applications. " Journal of Applied Biomedicine (De Gruyter Open) 6.2 (2008).

[22] Spinelle, Laurent, et al. "Review of portable and low-cost sensors for the ambient air monitoring of benzene and other volatile organic compounds." Sensors 17.7 (2017): 1520

[23] Williams, R., A. Kaufman, and S. Garvey. "Next generation air monitoring (NGAM) VOC sensor evaluation report." EPA: Washington, DC, USA (2015).

[24] Rinsky, R. A., et al. "Benzene exposure and hematopoietic mortality: A long-term epidemiologic risk assessment." American journal of industrial medicine 42.6 (2002): 474-480.

[25] Lewicki, Rafał, et al. "Spectroscopic benzene detection using a broadband monolithic DFB-QCL array." Novel In-Plane Semiconductor Lasers $X V$. Vol. 9767. International Society for Optics and Photonics, 2016.

[26] Sydoryk, Ihor, et al. "Detection of benzene and toluene gases using a midinfrared continuous-wave external cavity quantum cascade laser at atmospheric pressure." Applied optics 49.6 (2010): 945-949.

[27] Kleine, D., et al. "Measurement of the absolute intensity of the fifth $\mathrm{CH}$ stretching overtone of benzene using cavity ring-down spectroscopy." Chemical physics letters 312.2-4 (1999): 185-190.

[28] Sur, R., et al. "Tunable laser-based detection of benzene using spectrally narrow absorption features." Applied Physics B 125.11 (2019): 195.

[29] Wagner, Patrick, and Wilhelm Kuttler. "Biogenic and anthropogenic isoprene in the near-surface urban atmosphere-A case study in Essen, Germany." Science of the Total Environment 475 (2014): 104-115.

[30] Gupta, Manish. "Highly-precise measurements of ambient oxygen using near-infrared cavity-enhanced laser absorption spectrometry. " Analytical chemistry 84.18 (2012): 7987-7991.

[31] PNNL Spectroscopic Database, https://secure2.pnl.gov/nsd/nsd.nsf

[32] Gordon, Iouli E., et al. "The HITRAN2016 molecular spectroscopic database." Journal of Quantitative Spectroscopy and Radiative Transfer 203 (2017): 3-69.

[33] Swinehart, D. F. "The beer-lambert law." Journal of chemical education 39.7 (1962): 333. 
[34] Nasir, Ehson F., and Aamir Farooq. "Cavity-enhanced absorption sensor for carbon monoxide in a rapid compression machine." Proceedings of the Combustion Institute 37.2 (2019): 1297-1304.

[35] Kosterev, Anatoliy A., and Frank K. Tittel. "Chemical sensors based on quantum cascade lasers." IEEE journal of quantum electronics 38.6 (2002): 582-591.

[36] Corner, Laura, Hugh R. Barry, and Gus Hancock. "Comparison of crosssection measurements of the $2 v 5$ overtone band of formaldehyde determined by cavity ringdown and cavity enhanced spectroscopy." Chemical physics letters 374.1-2 (2003): 28-32.

[37] Wang, Zhennan, Chuji Wang, and Patty Lathan. "Breath acetone analysis of diabetic dogs using a cavity ringdown breath analyzer." IEEE Sensors Journal 14.4 (2013): 1117-1123.

[38] He, Qixin, et al. "Repetitively Mode-Locked Cavity-Enhanced Absorption Spectroscopy (RML-CEAS) for Near-Infrared Gas Sensing." Sensors 17.12 (2017): 2792.

[39] Nasir, Ehson F., and Aamir Farooq. "Intra-pulse laser absorption sensor with cavity enhancement for oxidation experiments in a rapid compression machine." Optics express 26.11 (2018): 14601-14609.

[40] Kosterev, Anatoliy A., et al. "Effective utilization of quantum-cascade distributed-feedback lasers in absorption spectroscopy." Applied optics 39.24 (2000): 4425-4430.

[41] Allan, David W. "Statistics of atomic frequency standards. " Proceedings of the IEEE 54.2 (1966): 221-230.

[42] Talvard, Thomas, et al. "Enhancement of the performance of a fiberbased frequency comb by referencing to an acetylene-stabilized fiber laser." Optics express 25.3 (2017): 2259-2269.

[43] Giglio, Marilena, et al. "Allan deviation plot as a tool for quartzenhanced photoacoustic sensors noise analysis." IEEE transactions on ultrasonics, ferroelectrics, and frequency control 63.4 (2015): 555-560.

[44] Alquaity, Awad BS, et al. "Detection of shock-heated hydrogen peroxide (H 2 O 2) by off-axis cavity-enhanced absorption spectroscopy (OACEAS). " Applied Physics B 123.12 (2017): 280.

[45] Berden, Giel, Rudy Peeters, and Gerard Meijer. "Cavity ring-down spectroscopy: Experimental schemes and applications." International Reviews in Physical Chemistry 19.4 (2000): 565-607.

[46] Sayres, David S., et al. "A new cavity based absorption instrument for detection of water isotopologues in the upper troposphere and lower stratosphere." Review of Scientific Instruments 80.4 (2009): 044102.

[47] Engel, Gregory S., et al. "Ultrasensitive near-infrared integrated cavity output spectroscopy technique for detection of $\mathrm{CO}$ at $1.57 \mu \mathrm{m}$ : new sensitivity limits for absorption measurements in passive optical cavities. " Applied optics 45.36 (2006): 9221-9229.

[48] Tittel, Frank K., Dirk Richter, and Alan Fried. "Mid-infrared laser applications in spectroscopy." Solid-state mid-infrared laser sources. Springer, Berlin, Heidelberg, 2003. 458-529.

[49] Roozeboom, C. L., et al. "Integrated sensor cross-sensitivity analysis." 2013 Transducers \& Eurosensors XXVII: The 17th International Conference on Solid-State Sensors, Actuators and Microsystems (TRANSDUCERS \& EUROSENSORS XXVII). IEEE, 2013.

[50] Hornberger, George M., and Robert C. Spear. "Approach to the preliminary analysis of environmental systems." J. Environ. Mgmt. 12.1 (1981): 7-18.

[51] Gardner, Lalita K., and Glen D. Lawrence. "Benzene production from decarboxylation of benzoic acid in the presence of ascorbic acid and a transition-metal catalyst." Journal of Agricultural and Food Chemistry 41.5 (1993): 693-695. 